\title{
Article
}

\section{The multi-component model of harmful sexual behaviour for people with autism and co-morbid intellectual disabilities - a theory and practice guide}

Worthington, Rachel Elizabeth

Available at http://clok.uclan.ac.uk/24956/

Worthington, Rachel Elizabeth (2019) The multi-component model of harmful sexual behaviour for people with autism and co-morbid intellectual disabilities - a theory and practice guide. The Journal of Forensic Practice, 21 (1). pp. 113. ISSN 2050-8794

It is advisable to refer to the publisher's version if you intend to cite from the work. http://dx.doi.org/10.1108/jfp-07-2017-0027

For more information about UCLan's research in this area go to http://www.uclan.ac.uk/researchgroups/ and search for <name of research Group>.

For information about Research generally at UCLan please go to http://www.uclan.ac.uk/research/

All outputs in CLoK are protected by Intellectual Property Rights law, including Copyright law. Copyright, IPR and Moral Rights for the works on this site are retained by the individual authors and/or other copyright owners. Terms and conditions for use of this material are defined in the policies page. 
The Multi-Component Model of Harmful Sexual Behaviour

for people with Autism and co-morbid Intellectual Disabilities - a Theory and Practice Guide.

\begin{tabular}{|r|l|}
\hline Journal: & Journal of Forensic Practice \\
\hline Manuscript ID & JFP-07-2017-0027.R4 \\
\hline Manuscript Type: & Practice Paper \\
\hline Keywords: & $\begin{array}{l}\text { autism, intellectual disability, harmful sexual behaviour, adults, therapy, } \\
\text { treatment }\end{array}$ \\
\hline
\end{tabular}


Title: The Multi-Component Model of Harmful Sexual Behaviour for people with Autism and comorbid Intellectual Disabilities - A Theory and Practice Guide.

\begin{abstract}
:
Purpose - The purpose of this paper is to explore to what extent neuro-typical theories of sexual offending apply to clients with Level 2 and Level 3 autism with a co-morbid intellectual disability. The paper develops a model of Harmful Sexual Behaviour for this client group and makes suggestions for how these behaviours can be understood and reduced.
\end{abstract}

Approach - The Revised Integrated Theory of Sexual Offending (Ward and Beech, 2016) is used as a starting framework to understand HSB in this client group. This attends to specific neuropsychological systems, brain development, motivation and emotional processing.

Findings: The Revised ITSO has some utility in understanding Harmful Sexual Behaviour in this client group. This is improved when neuro-atypical specific state factors are identified. Practical ways of establishing these state factors are made which attend to the function of the behaviour in-line with 'Good Lives' model of rehabilitation.

Practical implications: Recommendations for ways in which the function of HSB in this client group can be identified are made as well as recommendations for how treatment can be tailored dependent on the function of behaviour in this client group.

Originality/Value: Much of the work to date exploring HSB in clients with autism has attended to clients with Level 1 autism or those without an additional intellectual disability. This paper provides practitioners with a theory upon which to understand HSB in clients with a dual diagnosis of Level 2/3 autism and an intellectual disability as well as practical recommendations for reducing HSB in this client group. 


\section{Introduction:}

Both autistic spectrum disorders (ASD) and intellectual disabilities are neurodevelopmental disorders. An intellectual disability (ID) is identified using DSM-5 (APA, 2013) as:
a) A significantly reduced ability to understand complex information or learn new skills (impaired intelligence).
b) A reduced ability to cope independently (impaired social functioning).
c) The condition started before adulthood (18 years of age) and has a lasting effect (BPS, 2001).

The diagnostic criteria for ASD is listed in the DSM-5 (APA, 2013, p33) as:
A) Persistent deficits in social communication and social interaction across multiple contexts...
B) Restricted, repetitive patterns of behaviour, interests, or activities....
C) Symptoms must be present in the early developmental period....
D) Symptoms cause clinically significant impairment in social, occupational, or other important areas of current functioning....
E) These disturbances are not better explained by intellectual disability (intellectual developmental disorder) or global developmental delay...

Autism is categorised into 3 different levels of severity, recognising the spectrum of impairments and the severity of communication deficits and preoccupations with fixed rituals and/or repetitive behaviours:

Level 3 - Requiring very substantial support

Level 2 - Requiring substantial Support

Level 1- Requiring Support

This paper attends to people with autism at levels $2 / 3$ with an accompanying moderate intellectual disability who have engaged in Harmful Sexual Behaviour (HSB).

\section{Prevalence}

The prevalence of HSB in this population is difficult to establish because as King and Murphy (2014) note very few people with Level $2 /$ Level 3 autism with an additional moderate ID would be convicted 
of an offence because they are deemed not to have 'Mens Rea'. Hence, it is unlikely that the Crown Prosecution Service (CPS) would deem it to be in the public interest to prosecute them. Thus, much of the literature on offender populations with an ID tends to fall into the 'mild' rather than moderate category of ID (King and Murphy, 2014).

Realmuto and Ruble (1999) found inappropriate sexual behaviours were present in $29 \%$ of their sample of people with a autism and a mild to moderate ID (of whom $71 \%$ were in the 'moderate ID' category). Behaviours included public masturbation (21\%) followed by indecent exposure (7\%). However, in the sample of people with autism and no ID (sometimes referred to as 'high functioning'), inappropriate behaviours were only noted in $10 \%$ of the sample and also included inappropriate sexual interests in children. Thus, it is evident that HSB may be present in clients with autism and may manifest differently when the person has an additional ID. This paper will examine how this behaviour can be understood theoretically and how such behaviours can be reduced.

\section{Theories of Sexual Offending}

Ward and Beech (2016) identified inter-related factors associated with sexual offending, capturing these in the Revised Integrated Theory of Sexual Offending (ITSO) whereby brain development (genetics and evolution) influences biological functioning. Ecological niche factors (socio-cultural environment and personal situation) influence social learning. Both of these influence interlocking neuropsychological functions (motivation, emotion, and memory) which lead to changes in clinical symptoms (referred to as 'state factors') which results in sexual offending. In neuro-typical populations these have been identified as: general anti-sociality; deviant sexual arousal; problematic attitudes and beliefs; intimacy deficits; and problems with self-regulation. The model also includes factors which maintain sexual offending because social learning is influenced throughout a person's lifetime.

The ITSO model provides a holistic approach to considering the aetiology and maintenance of sexual offending integrating the research on risk factors for recidivism and theories of sexual offending. This paper will examine how the model may apply to sexual offenders with Level 2/3 autism and moderate ID. Each of the factors included in the model will be explored in terms of their application to this client group.

\section{Brain Development and Biological Functioning}


Ward and Beech (2016) proposed that genetic factors result in a predisposition to seek certain types of basic human needs. For example, sexual behaviour is evolutionary (Sterelny, 2012) but when this is combined with neurobiological differences in brain development (such as type and levels of neurotransmitters; the existence of neural pathways, the integrity of neural structures, high levels of stress hormones) this affects the action selection and control system.

Brain Wide Analysis (BWAS) has found that genetic alterations affect the biological pathways (Richards et al., 2015) causing weaknesses in: visual cortex (the region involved with facial expression processing); reduced connectivity with the ventromedial prefrontal cortex (linked with emotion and social communication) and weaknesses relating to reduced cortical functional connectivity for people with ASD. Atypical connectivity theories of autism (Catani et al., 2016) also find evidence of abnormal connectivity in the frontal lobes and regional differences in brain anatomy, which plays a key role in language and social function. In addition, Papagno et al (2010) also found diffusion abnormalities of the left uncinate fasciculus, which plays a significant role in face encoding and emotional processing associated with face perception.

Thus, brain development is clearly impacted upon for people with autism. Ways in which this may link with HSB are discussed subsequently.

\section{Ecological Niche}

Social, cultural and environmental influences may cause someone to commit a sexual offence in the absence of any significant psychological deficits or vulnerabilities (Ward and Beech, 2016). In terms of the development of HSB, these may be difficult to establish for people with Level $2 / 3$ autism due to limitations in the extent the person is aware of their ability to accurately perceive internal processes.

In neuro-typical populations research has shown that children learn to extinguish sexual behaviour because the social motivation hypothesis $(\mathrm{SMH})$ suggests they are motivated by: social rewards (such as facial expressions); the desire to shape others' perceptions of ourselves; and a desire to develop a sense of belonging (Chevallier et al., 2012). However, in ASD, reward centres are less activated for social stimuli and are less motivated to modify behaviour to make a good impression (Leary and Kowalski, 1990). Hence, studies have shown that children with ASD are less strategic in the way they present themselves compared to neuro-typical peers (Scheeren et al., 2010) and less able to use social cues to learn to inhibit sexual behaviours. Wurtele and Kenny (2011) note that by 
the age of 3, children engage in overt sexual behaviours such as exhibitionism (e.g. showing genitals to others), voyeuristic behaviours (e.g., looking at people undressing etc.), behaviours related to personal boundaries (e.g. cuddling with familiar people), and self-stimulating behaviours (e.g. touching genitals in public). However neuro-typical pre-school children (aged 3-6) are noted to have already become more inhibited at school compared to at home (Elkovitch et al., 2009). However, for children with autism this 'modesty' stage is less well developed and may extend into adolescence, whereby adolescents with ASD may fall behind their neuro-typical peers in their reputation management abilities, because social expectations and demands may exceed their development of social skills and a lack of motivation to please the audience (Scheeren et al., 2010).

The SMH provides some insight into how HSB may develop but the ITSO does not specify explicitly ecological niche factors as they are individualised to the person in a certain situation. However, this fits well with Applied Behaviour Analysis which attends to factors in the environment as triggers and reinforcers for behaviour and it is readily recognised as an important strategy for working with adults with autism and ID (Morano et al., 2017).

Interlocking neuropsychological functions (motivation, emotional, perception, memory, action selection and control)

The ITSO model proposes that in order to be motivated, information concerning the internal and external worlds needs to be available and interpreted meaningfully (perception and memory); and that in order to act, a plan needs to be selected and implemented successfully within a specific environment (action selection and control). Ward and Beech (2016) suggest that this requires core neuropsychological systems to be intact. For example, the motivation/emotional system which is associated with cortical, limbic, and brainstem brain structures which according to Pennington (2002) influences perception, action selection and the ability to adjust to changing environmental circumstances. Hence, if a person has difficulty recognising emotions they may struggle when confronted with the emotions of others and engage in an emotional response to cope with this (Pennington, 2002). In addition, when discussing the perception and memory system, the ITSO notes how this specifically relates to sensory information and to how a person constructs representations of their experiences in the environment (e.g. objects and events).

One of the strengths of the ITSO is that it regards these factors as interlocking neurological functions and vulnerability factors rather than 'dynamic risk factors' for sexual offending (Ward and Beech, 2016). This has particular significance for people with autism because the ability of people with 
Level 2/3 autism with a moderate ID to make mental representations of themselves and others is unlikely to be dynamic. For example, individuals with ASD experience deficits in social-emotional reciprocity, non-verbal communicative behaviours and the development, maintenance and understanding of relationships (APA, 2013). They also lack receptiveness or responsivity to facial expressions or typical social cues such as eye contact and body language (Wing, Gould and Gillberg, 2011) which is specifically evident for individuals with Level 3 autism.

Furthermore, it has been suggested that sexual offending in ASD may be linked to language impairments which impair social reciprocity (Haskins and Silva, 2006). These social difficulties, may be contributing factors to offending (Higgs and Carter, 2015) because they may fail to identify if a person disapproves of sexual behaviour through non-verbal communication (e.g. frowning, raised eyebrows, turning their eye gaze or direction of their head etc). Thus, they may continue with the behaviour rather than extinguishing it.

In addition, impairments in executive functioning and increased repetitive and perseverative qualities (Ozonoff and Strayer, 2001) in people with autism may be combined with weak central coherence (Baron-Cohen and Belmonte, 2005) leading to sensory difficulties which, if manifested in HSB can be associated with repetitive sexual behaviours such as masturbation regardless of the environment.

Deficits in social cognition and non-social domain general processing (inhibitory control and working memory; or weak central coherence), can result in a tendency to process constituent parts rather than perceiving the whole (Pellicano et al., 2006). Thus, poor impulse control may compromise decision making about whether to inhibit HSB. Robic et al. (2015) noted the social environment impacts on decision making for people with autism and Allman et al. (2005) attribute this to a deficit in the fast intuitive assessment of complex situations, due to difficulties in using formal social knowledge in quick-paced, rapidly shifting, social situations (Allman et al. 2005). This is worsened by deficits in: cognitive empathy (mind-blindness: a deficit in the ability to imagine the thoughts and feelings of others); and affective empathy (appropriate emotional responses to another person's thoughts and feelings) (Baron-Cohen, 2009). Higgs and Carter (2015) considered that the inability to be able to interpret another's intentions may play a key role in sexual offending.

\section{Clinical Symptoms/ State Factors (emotional problems, social difficulties, cognitive} distortions, deviant arousal) 
Neuro-typical state factors have been identified through factors associated with risk of recidivism (dynamic risk factors) in the ITSO and fall into 4 domains.

1) Emotional/behavioural regulation problems - impulsivity, poor emotional control.

2) Need for intimacy and control - social difficulties, emotional loneliness, inadequacy, low self-esteem, passive victim stance, and suspiciousness.

3) Offence-supportive cognitions or cognitive distortions - beliefs which support offending, e.g. believing that: the victim enjoys abuse; that the perpetrator is entitled to have sex; that women are deceitful.

4) Sexual interests - deviant sexual interest (or paraphilia).

However, dynamic risk factors pertaining to sexual offending are unknown for offenders with ASD (Higgs and Carter, 2015) and specifically when considering risk in clients with Level $2 / 3$ autism with co-morbid moderate ID. Neuro-developmental factors (attachment issues, low self-esteem and lack of assertiveness) have been highlighted as being linked to sexual offences in offenders with ID (Lindsay, 2009). In addition, Haskins and Silva (2006) state that a person with ASD may be more likely to engage in HSB due to: restricted or preoccupied interest of a sexual nature; reduced opportunities for adolescents to learn about sexuality and relationships within their peer group; and a reliance on other sources (such as the internet) for information which may provide inappropriate representations of sex and intimacy (Higgs and Carter, 2015). It is argued that this could lead to: the expectation that a sexual relationship develops quickly (Attwood, 2006); a lack of understanding around consent; focussing on their own needs over others; and a possible failure to recognise the distress of others (Haskins and Silva, 2006).

However, establishing the state factors for clients with comorbid Level $2 / 3$ autism and an ID appears to be an outstanding area in the ITSO. For example, whilst there is ample evidence that clients with autism and ID may experience increased emotional and behavioural regulation difficulties (Sutton et al., 2013) it is unclear how the factors 'need for intimacy' due to 'loneliness, inadequacy and low self-esteem' may apply to a person with autism where there is a high likelihood of them experiencing mind-blindness and alexithymia (Brewer, Cook and Bird, 2016).

In addition, given the neuropsychological deficits of this client group it would also be difficult to establish how an individual may adopt 'offence supportive cognitions' which require high 
levels of empathy. For example, the cognition 'women are deceitful' requires complex layers of knowledge: firstly that what someone else might think and feel is different to what the person with autism is thinking and feeling; that the other person would have the capacity to tell a lie; and that this lying occurs specifically in females towards males. Clearly this would require extensive cognitive flexibility, empathy and theory of mind which people with Level 3 autism and a moderate ID would be unlikely to possess.

Thus, the state factors identified in neuro-typical populations may have only limited applicability to HSB for people with Level 2/3 autism and ID. A potential method of identifying these for this client group could be undertaken through the use of functional assessment and Applied Behavioural Analysis ( $A B A$ ) in order to establish need fulfilment and the role of HSB when working with this client group. This will be explored subsequently.

Aunger and Curtis (2008) suggest that from an evolutionary perspective, the primary function of the brain is to produce adaptive behaviour in order to meet the person's needs called 'behaviour production units' (BPU's). BPU's can be divided into different functions: sensory systems at the 'front end' for recognizing stimuli; motor systems at the 'back end' for generating behaviour; and cognition and information processing for decision making (Harnish, 2001). Aunger and Curtis (2008) state behaviour occurs as a result of proposals by BPU's, the selection of one proposal and its execution by the peripheral nervous system. The time between BPU and selection of an action depends upon the 'time horizon' the person possesses as a result of memory or information processing. People with a longer time horizon can forego immediate reward behaviour for long term reward behaviour. Delays to selecting an action (even when the behaviour may be rewarding in the short term) are undertaken using executive control through forming robust mental representations of imagined future states (Ochsner and Gross, 2005). People with high level executive functions can 'metarepresent' or use 'interoception' (Sterelny, 2012) which is the ability to objectivise their own mental states (seeing themselves as having thoughts about their own thoughts) which allows temporary models of hypothetical situations to be created. People who do not have these skills have more reactive BPU based on responding to the person's current state and previous rewards in similar state situations to meet human needs. Thus, people with autism and an ID may have more difficulties foregoing immediate reward behaviours due to the deficits in calculating long term rewards and thus are likely to have a shorter 'time horizon'. In addition, behaviour selection is likely to be re-selected if sufficiently reinforced through the meeting of a need (Berridge, 2004). 
Research on people with ID and autism has sought to establish the fundamental needs behaviour is designed to achieve. This is consistent with managing state factors in the neurotypical population using the 'Good Lives' model (Ward and Brown, 2004). The benefit of this approach is that it overcomes difficulties in establishing the origin of HSB (which can be difficult to ascertain in people who are non-verbal) and moves towards understanding the function of the behaviour in the here and now.

These core fundamental needs (which act as reinforcers for problem behaviours) have been put into typologies. Matson and Vollmer (1995) identified these as:

- Attention - to get focused attention from others that are around them. This may not necessarily be verbal social interaction, but may include physical proximity of another or being able to express they are bored or need to make a request of some sort.

- Escape - to escape doing something he/she does not want to do or to reduce the demands being placed on them by people or the environment.

- Tangible reinforcement - to get a preferred item or participate in an enjoyable activity. Examples might include drinks, food, or being a preferred item (e.g. DVD).

- Physical discomfort - to cope with pain or discomfort which they are unable to express through other communicative functions.

- Sensory/non-social reinforcement - The individual behaves in a specific way because it feels good to them or regulates the central nervous system (such as sensory stimulation or self-soothing).

Hence, it could be hypothesized that the state factors associated with a risk of HSB in clients with autism and ID could be viewed as a behaviour which is designed to meet one of the aforementioned needs. This is reflected in the Multi-Component Model of HSB for people with autism and ID (see Figure 1) whereby the person enters a situation with certain vulnerabilities which are both biological and neurological and with prior learning of how sexual behaviour is paired with an outcome. When they experience a change in internal or external states which they seek to change, they can engage in HSB whereby the motivation is to influence sensory, attention, escape, physical or tangible stimuli. This then adjusts the person's internal or external stimulus and reinforces HSB as a means of achieving human 
needs. The social learning of prior HSB is kept as a vulnerability factor in the model because establishing the origins of social learning in adults with Level 2/3 autism and ID can often be difficult due to difficulties in recall and verbal expression. In addition, the model highlights that understanding the origin of social learning is not a pre-requisite for modifying HSB as this can be achieved through attending to the function of the behaviour for the individual as an adult. The following section explores how these functions of behaviour (or need factors) can be identified.

Figure 1 - Multi Component Model of Harmful Sexual Behaviour for people with Autism and ID

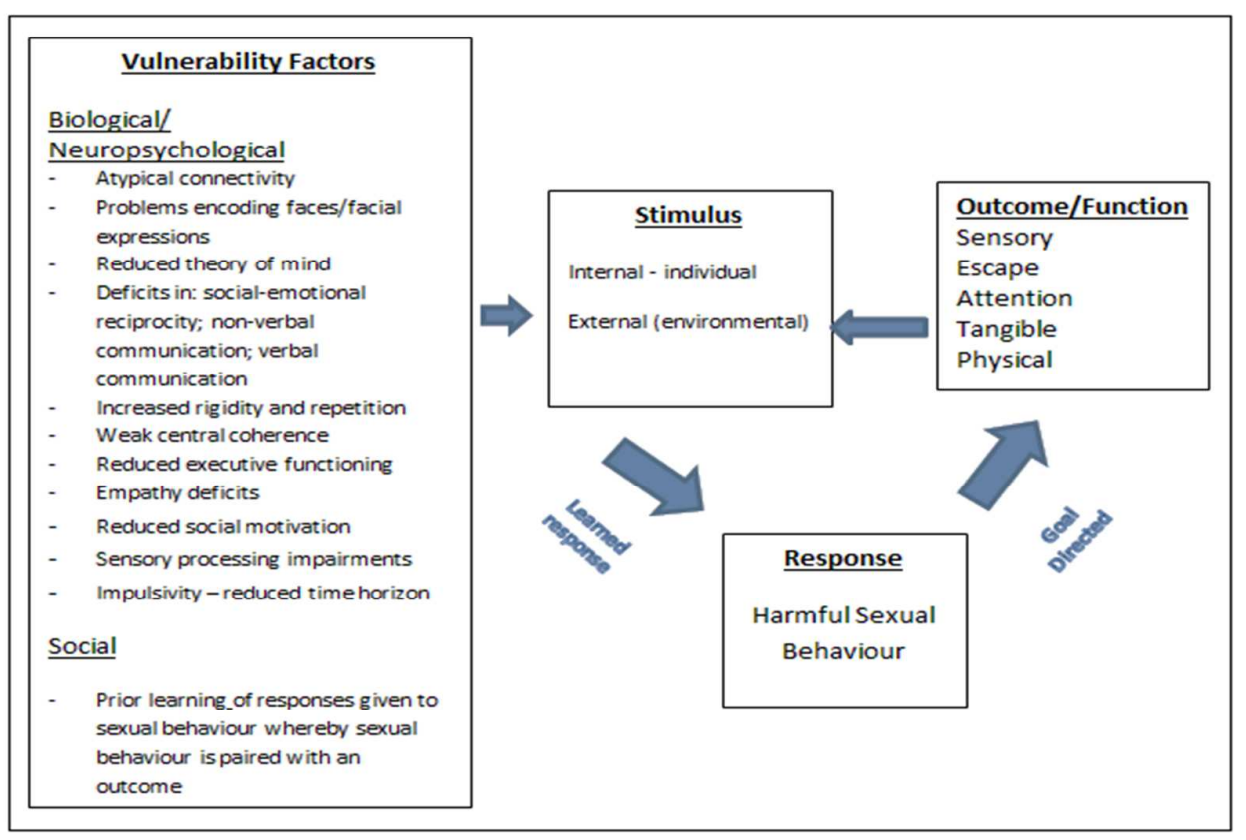

Positive Behaviour Support (PBS) uses functional assessment to identify the contingent relationship between: target behaviours; environmental antecedents; consequences; and the quality and duration of reinforcers (Linscheid et al., 1996) to develop functionally appropriate interventions (Sprague and Horner, 1995). The primary goal of PBS is to support the person to meet their needs in ways that improve their quality of life and includes an analysis of biological and social variables prior to treatment implementation (Van Houten et al, 1988). Thus, PBS maps well onto the revised ITSO and GLM models because it takes into account all of the factors which may contribute to a behaviour, as well as identifying the fundamental human need which the behaviour is achieving. Treatment focuses on: 
(1) Weakening the relationship between the target response and its maintaining reinforcer.

(2) Strengthening the response-reinforcement relationship of a substitute adaptive behaviour through teaching functional replacement behaviours and making modifications to the environment (Sprague and Homer, 1995).

PBS treatment interventions also target state factors as opposed to some of the interlocking neuropsychological functions and brain development which have less plasticity in this client group (e.g. perspective taking, impulse control etc). This mirrors interventions designed to reduce HSB in neuro-typical populations (Andrews and Bonta, 2010) but PBS also enables interventions to be targeted at an appropriate level for the individual. For example, current interventions in the neuro-typical client group and in the ID client group adopt cognitive behavioural therapy (CBT) based interventions to modify thinking patterns and behaviour and enable skills development (such as SOTSEC-ID: Murphy, Sinclair and Hays, 2010). Although these are well adapted for the ID population, they are not targeted at clients with Level 2 and 3 autism who are unlikely to be able to identify feelings and thoughts that contributed to their offending due to mindblindness, alexithymia, limited receptive and expressive verbal communication and difficulties with abstract concepts such as time (differentiating past and current thoughts). Hence, it is proposed that CBT interventions have questionable efficacy with this client group (Vollmer, Reyes, and Walker, 2012) whereas PBS allows a multicomponent behavioural intervention (MCBI).

Thus, the state factors and resultant treatment based on neuro-typical populations identified in the ITSO would seem to have limited applicability to clients with Level $2 / 3$ autism and a moderate ID. The following section suggests practical interventions which could be considered for each of the state factors for clients with Level 2/3 autism and an ID.

Sensory

According to Tomchek and Dunn (2007) sensory processing refers to the way the brain processes incoming sensory information (visual, auditory, tactile, taste, proprioceptive and vestibular input - processed in the cerebral cortex) in order to adapt to the environment. Incoming sensory stimuli is regulated in the neuro-typical population however, this is less adaptive in people with autism (Tomchek and Dunn, 2007). 
Sensory Processing consists of four quadrants of the sensory profile and how the central nervous system (CNS) receives messages from the senses and turns them into motor and behavioural responses (Tomchek and Dunn, 2007). These are:

1) low registration (the amount of sensory input to stimulate a person);

2) sensation seeking (where the person acts to seek out sensory stimulus);

3) sensory sensitivity (where the person does not require a large amount of stimulus to activate the central nervous system);

4) sensation avoiding (where the person actively avoids stimulus).

It is argued that sexualised behaviours may be an attempt by the individual to regulate the CNS which would explain why this behaviour is more prevalent in people with a sensory processing disorder such as adults with autism and ID. For example, the individual with a low neurological threshold requires a lower amount or intensity of stimuli to initiate awareness of and responses to stimulus. Conversely a high neurological threshold requires more intense stimulus for the nervous system to respond. Thus, a person with a high neurological threshold for touch (so they require a large amount of touch stimulus to process experiencing it) may engage in 'grabbing' of others in order to process touch sensations. This may serve two functions. Firstly, they may engage in more intensive touching of others because they cannot experience 'light' touch so they grab tightly because their body cannot sense they are holding another thus hurting the other unintentionally. Secondly, through a system of reinforcement they learn that 'grabbing' may result in physical restraint which provides large amounts of touch stimulus, thus meeting their threshold for touch stimulation and reinforcing HSB.

Hence, if the primary function of HSB is an attempt to regulate the CNS then specific interventions can be designed for this such as: developing a suitable living environment (Henry, 2012); creating sensory diets/menus (Bogdashina, 2003); and sensory design theory (Mostafa, 2014) to assist people with HSB, autism and ID to meet their sensory needs in more pro-social ways.

\section{Escape}

Escape relates to the person being overwhelmed with the environment due to the demands being placed upon them being too difficult due to the nature or complexity of the task. The instruction, 'Calm down and go and get your trainers on and don't forget to do the laces up. 
They are where you left them last time and then we can go out in 10 minutes to that new restaurant' would require the person to understand what 'calm' meant, how to 'calm themselves' to recall where their trainers were located, how to do them up, have the dexterity of movement to tie them and to understand the concept of time in terms of understanding how long 10 minutes is and to imagine a place they have never been to or seen. In such instances the person may engage in behaviours which result in the demand being removed (e.g. if they indecently expose themselves, others tell them they cannot go out and the overwhelming tasks are removed - negative reinforcement). Thus, HSB act as a means to escape (person or environmental) demands which are overwhelming.

Interventions could begin by undertaking baseline assessments of adaptive living skills and using 'Active Support' as a means of staggering the demands placed upon the individual. Active Support is a person-centred approach whereby the goal is to enable the person to be:

- engaged in doing things

- participating, making choices/decisions

- being active every day and throughout the day whenever there is an opportunity

- consistently providing enough structured support which is predictable

- engaging the person meaningfully in ways that provide enhanced esteem and are focused on the needs, preferences, and goals of the person.

Active Support is based on Seligman's (2011) PERMA model which had five core elements of psychological well-being and happiness to help people reach a life of fulfilment, happiness, and meaning. This also mirrors positive psychology approaches (e.g. the 'Good Lives Model') in terms of enabling a person to meet basic human needs. In Active Support, participation and providing the right level of assistance is promoted by using Activity Support Plans to organise: household tasks; personal self-care; hobbies; social arrangements etc. This is balanced with the right availability and grade of support the person requires. For example, a verbal prompt on how to use a toaster provides a lower level of assistance than hand on hand support to put the bread in the toaster. However, the purpose is to enable the individual to better tolerate demands for complex tasks and the support is person-centred. Active Support also maps onto the revised ITSO because it focusses on quality of life and meeting functional needs through pro-social means. In the example given, the person could be provided with hand on hand support to tie their shoe laces, prompts to set their stop watch so they can count down 10 minutes etc. 
Attention

One method through which the person may learn to obtain attention is through engaging in HSB. For example, 'John masturbates in the lounge causing staff to enter the lounge asking him to stop and asking if he would like to do something else'. In this function HSB is positively reinforced because the person receives attention as a result of HSB. Consequently, interventions in this function attend to teaching the person how they can receive attention in alternative ways. According to Trembath et al. (2014) adults with ASD and complex communication needs may benefit from using Augmentative and Alternative Communication $(A A C)$. AAC involves alternate methods of communicating needs, feelings, ideas, and perceptions through electronic and non-electronic devices that provide a means for expressive and receptive communication for people with limited or no speech.

Low tech AACs include, picture exchange communications systems (PECS), manual communication boards, symbols, visual schedules, signs and gestures (e.g. Makaton) etc. High tech $A A C$ 's include mobile phones, iPads with applications, videos for instructional training, robots, noise cancelling headphones, and reading aids such as coloured filters etc. Thus, new communicative behaviours are taught in order to replace behaviours of concern (see Chan et al., 2009) and this could extent to HSB.

$\underline{\text { Tangible }}$

Tangible positive reinforcement occurs when HSB is rewarded by a tangible item (e.g. drinks, food, or being offered something pleasurable such as a DVD). For example, the person could shout sexual words and threats towards another resulting in staff entering the room and saying 'calm down, why don't you come and have a cup of tea'. Hence, interventions involve teaching the person to use AAC to communicate their need for tangible items. If they did not have the vocabulary to describe hunger or thirst or have the self-awareness to recognize this was the emotion they were experiencing they could be taught the name for when their tongue feels dry as being 'thirsty' and that having a drink may help with this. Aids such as Social Stories ${ }^{\mathrm{TM}}$ (Gray, 2000) could assist the person to recognize (using imagery) 'when I am thirsty my tongue feels dry. When my tongue feels dry I could show my cup to a member of staff and say the word drink'. In addition, aids such as 'now and next' and visual planners may assist the person to recognise what time of day it is and what happens at that time of day (such as when they will next have a drink). Thus, the function of HSB in this instance relates 
to obtaining tangible rewards which the person could be taught alternative methods of obtaining.

Physical

In the case of Level 3 autism the person may not be able to name the part of the body that hurts or even point to it, or to recognise that the different feeling that part of the body is experiencing is pain. HSB in response to this could be, for example someone who excessively masturbates against public objects as a means of distracting their attention from pain in a part of their body elsewhere (e.g. toothache). Thus, interventions with a Speech and Language Therapist (SaLT) could teach the person to locate and point to different parts of their body, to communicate if that part of the body feels 'good' or 'bad' and how to point to ask for a tablet or medicine. Social Stories ${ }^{\mathrm{TM}}$ could teach them what to expect when they attend a GP/Dentist (e.g. who might be there, what to expect in the environment, potential smells or equipment that might be there).

\section{$\underline{\text { Multi-functional }}$}

It is important to note that a person may use one behaviour (e.g. public masturbation) as a means of achieving multiple functions. For example, they may do this when: they are bored to obtain attention; to regulate sensory input; when they are overwhelmed; when they want an item; and/or when they are in pain. Hence, people in this category would require the full range of interventions. Thus, as with any $A B A$ it is imperative that the function(s) of the behaviour are clearly established from the outset in order to determine which (or all) of the interventions may be of benefit.

\section{Conclusions and Recommendations}

As with neuro-typical populations, HSB in people with autism and ID can be regarded as having multiple components. In addition, the benefit of identifying the function of the behaviour is that it provides potential alternative methods of achieving an outcome without the need for HSB. Thus, by attending to the function and using autism specific methods to compensate for neuropsychological deficits this provides a promising basis upon which HSB in this client group could be reduced. Furthermore, this model has the benefit of being behaviourally based, multi-factorial and focused on attending to human needs and quality of life. However, it is noted that the limitations of the model are that it applies to a very specific 
client group and future research should seek to explore both the utility of the model with this client group as well as if the model can be generalised across populations (e.g. females, adolescents etc.).

Implications for practice

- $\quad \mathrm{CBT}$ based interventions based on the state factors for a neuro-typical population may lack applicability for clients with Level 2 and Level 3 autism and ID. This is not a criticism of the revised ITSO which noted that sexual offending treatment should be targeted at a multi-level approach. This is consistent with Ward, Clack and Haig (2016) who argued that effective treatment of harmful sexual behaviour should involve a case formulation and the Abductive Theory of Method (ATOM), which acknowledges that treatment could extend beyond CBT for attending to state factors. This model proposes methods by which interventions attend to the neuropsychological functioning of an individual.

- Future interventions for clients with autism and ID should attend to Functional Behavioural Assessment (FBA) with a precise description of the behaviour, its context, and its consequences. This should include an environmental assessment, direct observation, understanding setting events and slow triggers, fast triggers, interview data from people supporting the individual and $A B C$ data which specifically attends to the consequences of behaviour to ascertain functionality. Data on medical history, medication and physical and biological factors should also be gathered in order to ascertain the inter-locking neuropsychological functions which the person brings to the situation.

- Interventions for managing HSB for people with Level 2/3 autism and ID should match the function of the behaviour and assist the person to meet their human needs in ways that do not involve HSB and instead promote quality of life which would is consistent with desistance theories and a genuine good life plan (GLP) or a unique "roadmap" (Yates, Prescott and Ward, 2010, p.155). 'Treatment' is not a pre-requisite for acquiring capabilities and this should attend to both the internal and external conditions required to implement a good lives plan (Laws and Ward, 2011).

- Future treatments for HSB in clients with autism and ID could include providing sensory diets to meet sensory needs, teaching alternative strategies for seeking out 'deep pressure' or attention in ways that do not involve HSB, using picture communication, information technology or Makaton to communicate needs or using Social Stories ${ }^{\mathrm{TM}}$ to explain the consequences of behaviour. 
- Neuro-atypical interventions which attend to the neuropsychological functioning of clients (such as sensory diets) could also be included in treatment for neuro-typical clients thus ensuring that interventions attend to every aspect of the ITSO and not purely state factors. 


\section{$\underline{\text { References }}$}

Allman, J.M., Watson, K.K., Tetreault, N.A. and Hakeem, A.Y., 2005. Intuition and autism: a possible role for Von Economo neurons. Trends in cognitive sciences, 9(8), pp.367-373.American Psychiatric Association, 2013. Diagnostic and statistical manual of mental disorders (DSM-5 $\left.{ }^{\circledR}\right)$. American Psychiatric Pub.

Andrews, D.A. and Bonta, J., 2014. The psychology of criminal conduct. Routledge.

Attwood, T., 2006. The complete guide to Asperger's syndrome. Jessica Kingsley Publishers.

Aunger, R. and Curtis, V., 2008. Kinds of behaviour. Biology \& philosophy, 23(3), pp.317-345.

Baron-Cohen, S., 2009. Autism: the empathizing-systemizing (E-S) theory. Annals of the New York Academy of Sciences, 1156(1), pp.68-80.

Baron-Cohen, S. and Belmonte, M.K., 2005. Autism: a window onto the development of the social and the analytic brain. Annu. Rev. Neurosci., 28, pp.109-126.

Berridge, K. C., 2004. Motivation concepts in behavioral euroscience. Physiology and Behavior, 81,179-209.

Bogdashina, O., 2003. Sensory Perceptual Issues in Autism and Asperger Syndrome: Different Sensory Experiences. Different Perceptual Worlds, Jessica Kingsley, London, UK.

Brewer, R., Cook, R. and Bird, G., 2016. Alexithymia: a general deficit of interoception. Royal Society open science, 3(10), p.150664.

British Psychological Society, 2001. Learning Disability: Definitions and contexts. Leicester: British Psychological Society.

Catani, M., Dell'Acqua, F., Budisavljevic, S., Howells, H., Thiebaut de Schotten, M., Froudist-Walsh, S., D’Anna, L., Thompson, A., Sandrone, S., Bullmore, E.T. and Suckling, J., 2016. Frontal networks in adults with autism spectrum disorder. Brain, 139(2), pp.616-630.

Chan, J.M., Lang, R., Rispoli, M., O’Reilly, M., Sigafoos, J. and Cole, H., 2009. Use of peer-mediated interventions in the treatment of autism spectrum disorders: A systematic review. Research in Autism Spectrum Disorders, 3(4), pp.876-889.

Chevallier, C., Kohls, G., Troiani, V., Brodkin, E.S. and Schultz, R.T., 2012. The social motivation theory of autism. Trends in cognitive sciences, 16(4), pp.231-239.

Elkovitch, N., Latzman, R.D., Hansen, D.J. and Flood, M.F., 2009. Understanding child sexual behavior problems: A developmental psychopathology framework. Clinical Psychology Review, 29(7), pp.586598.

Gray, C., 2000. The new social story book. Future Horizons.

Harnish, R., 2001. Minds, Brains, Computers: An Historical Introduction to the Foundations of Cognitive Science. Blackwell, London.

Haskins, B.G. and Silva, J.A., 2006. Asperger's Disorder and Criminal Behavior: Forensic-Psychiatric Considerations Asperger's Disorder and Criminal Behavior: Forensic-Psychiatric Considerations. J Am Acad Psychiatry Law, 34(3), pp.374-384. 
Henry, C., 2012. Architecture for Autism: Architects Moving in the Right Direction. Arch Daily, January 5th.

Higgs, T. and Carter, A.J., 2015. Autism spectrum disorder and sexual offending: Responsivity in forensic interventions. Aggression and violent behavior, 22, pp.112-119.

King, C. and Murphy, G.H., 2014. A systematic review of people with autism spectrum disorder and the criminal justice system. Journal of autism and developmental disorders, 44(11), pp.2717-2733.

Lang, R., O’Reilly, M., Healy, O., Rispoli, M., Lydon, H., Streusand, W., Davis, T., Kang, S., Sigafoos, J., Lancioni, G. and Didden, R., 2012. Sensory integration therapy for autism spectrum disorders: A systematic review. Research in Autism Spectrum Disorders, 6(3), pp.1004-1018.

Laws, D.R. and Ward, T., 2011. Desistance from sex offending: Alternatives to throwing away the keys. Guilford Press.

Leary, M. R.and Kowalski, R. M., 1990. Impression management: A literature review and twocomponent model. Psychological Bulletin, 107 (1), 34-47.

Lindsay, W.R., 2009. The treatment of sex offenders with developmental disabilities: A practice workbook. John Wiley \& Sons.

Linschied, T.R., Iwata B.A. and Ricketts, R.W., 1990. Clinical evaluation of the self-injurious behaviour inhibiting system (SIBIS). Journal of Applied Behaviour Analysis 23 53-78.

Matson, J.L. and Vollmer, T.R., 1995. User's guide: Questions about behavioral function (QABF). Baton Rouge, LA: Scientific Publishers.

Morano, S., Ruiz, S., Hwang, J., Wertalik, J.L., Moeller, J., Karal, M.A. and Mulloy, A., 2017. Metaanalysis of single-case treatment effects on self-injurious behavior for individuals with autism and intellectual disabilities. Autism \& Developmental Language Impairments, 2, p. 2396941516688399.

Mostafa, M., 2014. Architecture for Autism: Autism ASPECTSS ${ }^{\text {TM }}$ in School Design. International Journal of Architectural Research: ArchNet-IJAR, 8(1), pp.143-158.

Murphy, G.H., Sinclair, N. and Hays, S.J., 2010. SOTSEC-ID. Effectiveness of group cognitive behavioural treatment for men with intellectual disabilities at risk of sexual offending. J App Res Intellect Disabil, 23, pp.537-551.

Ochsner, K. N. and Gross, J. J., 2005. The cognitive control of emotion. Trends in Cognitive Sciences, 9.

Ozonoff, S. and Strayer, D.L., 2001. Further evidence of intact working memory in autism. Journal of autism and developmental disorders, 31(3), pp.257-263.

Papagno, C., Miracapillo, C., Casarotti, A., Romero Lauro, L.J., Castellano, A., Falini, A., Casaceli, G., Fava, E. and Bello, L., 2010. What is the role of the uncinate fasciculus? Surgical removal and proper name retrieval. Brain, 134(2), pp.405-414.

Pellicano, E., Maybery, M., Durkin, K. and Maley, A., 2006. Multiple cognitive capabilities/deficits in children with an autism spectrum disorder: "Weak" central coherence and its relationship to theory of mind and executive control. Development and psychopathology, 18(1), pp.77-98. 
Pennington, B.F., 2002. The development of psychopathology: Nature and nurture. Guilford Press.

Realmuto, G. M., and Ruble, L. A., 1999. Sexual behaviors in autism: problems of definition and management. Journal of Autism and Developmental Disorders,29, 121-127.

Richards, C., Jones, C., Groves, L., Moss, J. and Oliver, C., 2015. Prevalence of autism spectrum disorder phenomenology in genetic disorders: a systematic review and meta-analysis. The Lancet Psychiatry, 2(10), pp.909-916.

Robic, S., Sonié, S., Fonlupt, P., Henaff, M.A., Touil, N., Coricelli, G., Mattout, J. and Schmitz, C., 2015. Decision-making in a changing world: a study in autism spectrum disorders. Journal of autism and developmental disorders, 45(6), pp.1603-1613.

Scheeren, A. M., Begeer, S., Banerjee, R., Meerum Terwogt, M., and Koot, H. M., 2010. Can you tell me something about yourself? Self-presentation in children and adolescents with high functioning autism spectrum disorder in hypothetical and real life situations. Autism, 14(5), 457-473.

Seligman, M., 2011. What you can change... and what you can't. Nicholas Brealey Publishing.

Seligman, M.E., 2011. Flourish: a visionary new understanding of happiness and well-being. Policy, 27(3), pp.60-1.

Sprague, J.R. and Horner, R.H., 1995. Functional assessment and intervention in community settings. Mental Retardation and Developmental Disabilities Research Reviews, 1(2), pp.89-93

Sterelny, K., 2012. The evolved apprentice. MIT press.

Sutton, L.R., Hughes, T.L., Huang, A., Lehman, C., Paserba, D., Talkington, V., Taormina, R., Walters, J.B., Fenclau, E. and Marshall, S., 2013. Identifying individuals with autism in a state facility for adolescents adjudicated as sexual offenders: a pilot study. Focus on autism and other developmental disabilities, 28(3), pp.175-183.

Tomchek, S.D. and Dunn, W., 2007. Sensory processing in children with and without autism: a comparative study using the short sensory profile. American Journal of occupational therapy, 61(2), pp.190-200.

Trembath, D., lacono, T., Lyon, K., West, D. and Johnson, H., 2014. Augmentative and alternative communication supports for adults with autism spectrum disorders. Autism, 18(8), pp.891-902.

Van Houten, R., Axelrod, S., Bailey, J.S., Favell, J.E., Foxx, R.M., Iwata, B.A. and Lovaas, O.I., 1988. The right to effective behavioral treatment. Journal of Applied Behavior Analysis, 21(4), pp.381-384.

Vollmer, T.R., Reyes, J.R. and Walker, S.F., 2012. Behavioral assessment and intervention for sex offenders with intellectual and developmental disabilities. The handbook of high-risk challenging behaviors in people with intellectual and developmental disabilities, pp.121-144.

Vrtička, P., Andersson, F., Grandjean, D., Sander, D. and Vuilleumier, P., 2008. Individual attachment style modulates human amygdala and striatum activation during social appraisal. PLoS One, 3(8), p.e2868. 
Ward, T. and Beech, A.R., 2016. The Integrated Theory of Sexual Offending-Revised. The Wiley Handbook on the Theories, Assessment and Treatment of Sexual Offending.

Ward, T. and Brown, M., 2004. The good lives model and conceptual issues in offender rehabilitation. Psychology, Crime \& Law, 10(3), pp.243-257.

Ward, T., Clack, S. and Haig, B.D., 2016. The abductive theory of method: Scientific inquiry and clinical practice. Behaviour Change, 33(4), pp.212-231.

Wing, L., Gould, J. and Gillberg, C., 2011. Autism spectrum disorders in the DSM-V: better or worse than the DSM-IV?. Research in developmental disabilities, 32(2), pp.768-773.

Wurtele, S.K. and Kenny, M.C., 2011. Normative sexuality development in childhood: Implications for developmental guidance and prevention of childhood sexual abuse. Counseling and Human Development, 43(9), p.1.

Yates, P.M., Prescott, D. and Ward, T., 2010. Applying the good lives and self-regulation models to sex offender treatment. Brandon: Safer Society. 